\title{
Penerapan Program GSTAT-R untuk Prediksi Kadar Abu Batubara di Lokasi Tidak Tersampel dengan Metode Universal Kriging
}

\author{
Annisa Nur Falah, Betty Subartini, Budi N. Ruchajana \\ Program Studi Matematika FMIPA Universitas Padjadjaran \\ Jl. Raya Bandung Sumedang Km 21 Jatinangor, Sumedang 45363 \\ e-mail: annisanurfalah02@gmail.com, budinr@unpad.ac.id
}

\begin{abstract}
ABSTRAK
Geostatistika merupakan perpaduan ilmu pertambangan, geologi, matematika, dan statistika. Data yang digunakan dalam geostatistika merupakan data spasial yakni nilai pengamatan berdasarkan lokasi. Kriging merupakan metode penaksiran yang menggunakan data spasial yang bertujuan untuk menaksir nilai di suatu lokasi, berupa titik atau blok berdasarkan informasi nilai-nilai dari lokasi lain di sekitar lokasi yang akan ditaksir. Dalam paper ini akan dibahas mengenai metode universal kriging, karena data yang diprediksi merupakan data yang tidak stasioner.Universal kriging adalah metode interpolasi data yang mempunyai kecenderungan trend (drift) tertentu atau metode penaksiran yang digunakan untuk menangani masalah kenonstasioneran dari data sampel. Dengan menggunakan program GSTAT-R perhitungan hasil prediksi di lokasi tidak tersampel pada metode universal kriging ini didapat dengan persamaan trend (drift) berorde satu. Prediksi kadar abu batubara dilokasi tidak tersampel pada program GSTAT-R dengan menggunakan metode universal kriging menghasilkan hasil prediksi yang akurat.
\end{abstract}

Kata kunci : data spasial, kriging, stasioner, trend (drift), universal kriging.

\section{Pendahuluan}

Geostatistika merupakan perpaduan ilmu pertambangan, geologi, matematika, dan statistika [3]. Data yang dipergunakan dalam geostatistika merupakan data spasial yakni nilai pengamatan berdasarkan lokasi. Di dalam geostatistika terdapat suatu proses prediksi yang digunakan untuk melakukan estimasi cadangan mineral. G. Matheron menamakan proses prediksi ini sebagai kriging [4]. Kriging merupakan metode penaksiran yang menggunakan data spasial. Proses perhitungan kriging dapat dibedakan beberapa macam, yakni: Point kriging, Block kriging, Co-kriging, Universal kriging. Universal kriging adalah kriging dari data yang mempunyai kecenderungan trend tertentu. Universal kriging juga dapat diartikan sebagai metode penaksiran yang digunakan untuk menangani masalah kenonstasioneran dari data sampel. Sebagai contoh, data yang digunakan pada skripsi ini adalah data sekunder di dalam program GSTAT yang diberi nama data coalash, yaitu data kadar abu batubara yang diperoleh dari hasil eksplorasi Gomez dan Hazen pada tahun 1970 sebanyak 208 lokasi di daerah Greene County, Pennsylvania, Amerika Serikat.

Program GSTAT adalah sebuah program untuk model geostatistika, prediksi, dan simulasi dalam satu, dua, atau tiga dimensi yang terdiri dari perhitungan sampel variogram, cross variogram dan mencocokan model. Pada awalnya program ini berdiri sendiri, namun pada tahun 2004 dibuat paket dalam software $\mathrm{R}$ sebagai salah satu paket pengolah data spasial yang berisi fungsi-fungsi atau perintah program pengolah aplikasi Geostatistika [2]. Sehingga dalam penelitian ini untuk menganalisis metode Universal kriging dapat menggunakan program GSTAT berbasis software R.

\section{Semivariogram dan Metode Universal Kriging}

3.

\subsection{Semivariogram Eksperimental}

Menurut [1] mengembangkan hipotesis intrinsik yang artinya bahwa rataan dan varians dari pergeseran $[Z(x+h)-Z(x)]$ tidak tergantung pada posisi lokasi $x$ atau didefinisikan sebagai: 


$$
\begin{aligned}
& E[Z(x+h)-Z(x)]=0 \\
& \operatorname{Var}[Z(x+h)-Z(x)]=2 \gamma(h)
\end{aligned}
$$

Dengan fungsi $\gamma(h)$ disebut semivariogram.

Berdasarkan persamaan (2.1) dan (2.2) maka semivariogram eksperimental dapat didefinisikan :

$$
\hat{\gamma}(h)=\frac{1}{2 N(h)} \sum_{i=1}^{N(h)}\left[Z\left(x_{i}+h\right)-Z\left(x_{i}\right)\right]^{2}
$$

Keterangan :

$$
\begin{aligned}
\hat{\gamma}(h) & =\text { nilai semivariogram eksperimental dengan jarak } h \\
Z\left(x_{i}\right) & =\text { nilai pengamatan di titik } x_{i} \\
Z\left(x_{i}+h\right) & =\text { nilai pengamatan di titik } x_{i}+h \\
N(h) & =\text { banyaknya pasangan titik yang berjarak } h
\end{aligned}
$$

\subsection{Model Semivariogram Teoretis}

Semivariogram memberikan kuantifikasi obyektif, karena melibatkan jarak dan arah. Dalam hal ini dipilih tiga model semivariogram teoritis yaitu model Spheris, Gauss dan Eksponensial [1].

\section{Spherical Model}

$$
\gamma(h)= \begin{cases}\mathrm{c}\left[1,5\left(\frac{h}{a}\right)-0,5\left(\frac{h}{a}\right)^{3}\right], & h<a \\ c, & h \geq a\end{cases}
$$

\section{Gaussian Model}

$$
\gamma(h)= \begin{cases}c\left[1-\exp \left(\frac{-h^{2}}{a^{2}}\right)\right], & h<a \\ c, & h \geq a\end{cases}
$$

\section{Model Eksponensial}

$$
\gamma(h)= \begin{cases}c\left[1-\exp \left(\frac{-h}{a}\right)\right], & h<a \\ c, & h \geq a\end{cases}
$$

dengan :

$h=$ jarak antar dua lokasi

$c=$ Sill

$a=$ range

\subsection{Metode Universal Kriging}

Universal kriging merupakan salah satu metode kriging yang memiliki asumsi bahwa rata-rata (mean) tidak konstan. Jika $m(x)$ adalah persamaan trend (drift), dengan persamaan sebagai berikut [4]: 


$$
m(x)=\sum_{l=0}^{n} a_{l} f_{l}(x)
$$

Karena $m$ tidak konstan, maka diperoleh estimator universal kriging sebagai berikut:

$$
\begin{aligned}
& \hat{Z}\left(x_{0}\right)-m=\sum_{i=1}^{k} \lambda_{i}\left[Z\left(x_{i}\right)-m\right] \\
& \hat{Z}\left(x_{0}\right)-m(x)=\sum_{i=1}^{k} \lambda_{i}\left[Z\left(x_{i}\right)-m(x)\right] \\
& \hat{Z}\left(x_{0}\right)=m(x)+\sum_{i=1}^{k} \lambda_{i}\left[Z\left(x_{i}\right)-m(x)\right]
\end{aligned}
$$

\section{Tahap Pencocokan Model Semivariogram Teoritis dengan Semivariogram Eksperimental}

Sebelum melakukan pencocokan model semivariogram teoritis dengan semivariogram eksperimental diperlukan beberapa tahap. Tahap pertama yaitu menginputkan data. Aktifkan GSTAT dengan mengetikan perintah tersebut:

$$
\begin{aligned}
& >\text { library(sp) } \\
& \text { > library(gstat) }
\end{aligned}
$$

Setelah pengaktifan program GSTAT, input dataset coalash dengan cara sebagai berikut:

$$
>\text { data(coalash) }
$$

Tahap kedua adalah menghitung semivariogram eksperimental pada GSTAT dengan melibatkan fungsi variogram yaitu:

$$
>\text { v.coalash1<-variogram(object,data) }
$$

\section{Keterangan:}

v.coalash1 : Nama hasil perhitungan semivariogram ekperimental

object $\quad$ : Objek data yang digunakan dengan koordinat data

data : Nama dataset

Untuk menampilkan nilai semivariogram eksperimental dan menampilkan dalam diagram pencar dapat menggunakan perintah sebagai berikut:

$$
\begin{aligned}
& >\operatorname{print}(\mathrm{v} \cdot \text { coalash1) } \\
& >\operatorname{plot}(\mathrm{v} \cdot \mathrm{coalash} 1)
\end{aligned}
$$

Tahap ketiga adalah menghitung semivariogram teoritis pada GSTAT, perintah yang dapat digunakan adalah:

Keterangan:

$$
>\text { v.coalash2<-vgm(psill=varians,model="Exp",range) }
$$

v.coalash2 : Hasil dari penentuan model dasar semivariogram eksponensial.

psill : Nilai variansi dari data yang digunakan.

model : Jenis model yang digunakan.

range $\quad$ : Jarak pada sumbu mendatar yang mengandung sill.

Setelah diperoleh model semivariogram eksponensial, tahap keempat adalah tahap pencocokan model semivariogram eksponensial dengan semivariogram eksperimental menggunakan perintah:

$$
\text { > v.coalash3<-fit.variogram(v.coalash1,v.colash2) }
$$


Keterangan:

v.coalash3

: Hasil dari pencocokan model semivariogram eksponensial dengan semivariogram eksperimental.

Pada proses ini, terjadi pengulangan dalam menentukan nilai range pada model semivariogram eksponensial untuk mendapatkan hasil psill=varians. Untuk melihat hasil dari pencocokan model semivariogram eksponensial dengan semivariogram eksperimental dapat menggunakan perintah:

$$
>\text { plot(v.coalash1, model=v.coalash } 3)
$$

\subsection{Prediksi Nilai yang Tidak Tersampel Menggunakan Metode Universal Kriging}

Universal kriging adalah kriging dari data yang mempunyai kecenderungan trend tertentu. Metode Universal kriging adalah metode penaksiran yang digunakan untuk menangani masalah kenonstasioneran dari data sampel. Tujuan utama dari metode Universal kriging adalah untuk menghasilkan nilai taksiran dengan variansi minimum.

Dalam menentukan koefisien persamaan trend (drift) orde satu dapat menggunakan perintah sebagai berikut:

$$
>\text { fit }<-\operatorname{lm}(\text { coalash } \sim \mathrm{x}+\mathrm{y})
$$

Selanjutnya adalah menghitung prediksi nilai yang tidak tersampel dengan menggunakan metode Universal kriging dapat menggunakan perintah:

Keterangan:

$$
>\text { uk<-krige(coalash } \sim \mathrm{x}+\mathrm{y} \text {,locations,newdata,model) }
$$

Newdata

: Lokasi data yang akan diestimasi.

Model

: Model fitting semivariogram eksperimental dan semivariogram Eksponensial

\section{Pembahasan}

\subsection{Program GSTAT pada Data Coalash}

Data Penelitian yang digunakan adalah data sekunder dalam program R. Dataset yang diambil bernama data coalash yaitu data kadar abu batubara yang diperoleh dari hasil eksplorasi Gomez dan Hazen.

Tabel 4.1 Data Kadar Abu Batubara pada Tahun 1970 sebanyak 208 lokasi di Daerah Greene County, Pennsylvania, Amerika serikat.

\begin{tabular}{|c|c|c|c|}
\hline Lokasi ke- & $\boldsymbol{x}(\boldsymbol{m})$ & $\boldsymbol{y}(\boldsymbol{m})$ & Coalash (ppm) \\
\hline $\mathbf{1}$ & 1 & 14 & 10.21 \\
\hline $\mathbf{2}$ & 1 & 15 & 9.92 \\
\hline$\ldots$ & $\ldots$ & $\ldots$ & $\ldots$ \\
\hline $\mathbf{2 0 7}$ & 15 & 19 & 9.91 \\
\hline $\mathbf{2 0 8}$ & 16 & 17 & 9.07 \\
\hline
\end{tabular}

Sumber: Dataset pada Program R 3.1.1

Dengan menggunakan program R.3.1.1 penyebaran data kadar abu batubara dapat dilihat dengan menggunakan perintah berikut:

Klik Graphs pada menu bar R commander -> 3D Graph sehingga akan tampak seperti pada Gambar 4.1 


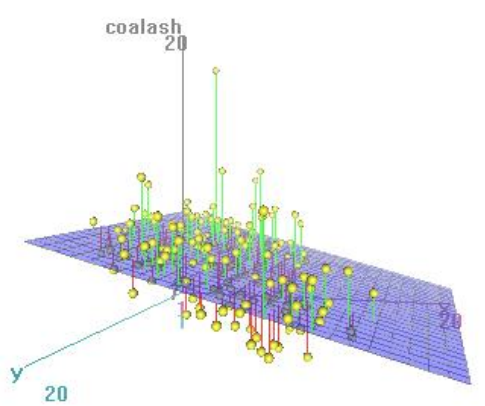

Gambar 4.1 Sebaran Data Abu Batubara pada Diagram Pencar Sumbu $x, y$ dan $z$.

Selanjutnya data dari Tabel 4.1 dapat diringkas, seperti terlihat pada Gambar 4.2, dengan menggunakan perintah:

$$
>\text { summary(coalash) }
$$

Berikut merupakan hasil ringkasan data kadar abu batubara pada Tabel 4.1

Tabel 4.2 Statistika Deskriptif Data Kadar Abu Batubara (Coalash)

\begin{tabular}{|c|c|c|c|}
\hline & $\boldsymbol{x}(\boldsymbol{m})$ & $\boldsymbol{y}(\boldsymbol{m})$ & Coalash $(\boldsymbol{p p m})$ \\
\hline Minimum & 1.000 & 1.00 & 7.000 \\
\hline $\mathbf{1}^{\text {st }}$ Quartil & 5.000 & 8.00 & 8.960 \\
\hline Median & 7.000 & 13.00 & 9.785 \\
\hline Mean & 7.534 & 12.91 & 9.779 \\
\hline 3 Quartil & 10.000 & 18.00 & 10.568 \\
\hline Maximum & 16.000 & 23.00 & 17.610 \\
\hline
\end{tabular}

Table 4.2 memperlihatkan ringkasan data berdasarkan titik koordinat $x$ (absis $x$ ) yang memiliki nilai minimum $1,000 \mathrm{~m}$ dan maksimum $16,000 \mathrm{~m}$, koordinat $y$ (ordinat $y$ ) memiliki nilai minimum 1,00 $\mathrm{m}$ dan nilai maksimum 23,00 $\mathrm{m}$, sedangkan untuk kadar abu batubara (coalash) memiliki nilai minimum 7,000 ppm dan maksimum 17,610 ppm.

\subsection{Pengujian Stasioneritas}

Pada ordinary kriging diperlukan asumsi data yang bersifat stasioner orde dua, sedangkan pada universal kriging stasioneritas orde dua tidak berlaku, sehingga dari keseluruhan data tersebut dilakukan ploting data untuk dapat mengetahui apakah data yang diperoleh stasioner atau tidak. Kestasioneritasan akan terlihat setelah titik-titik kandungan tersebut di plotkan dan akan terlihat apakah data memiliki kecenderungan trend atau tidak. Berikut ini adalah plot sebaran data berdasarkan Tabel 4.1

Plot Absis dan Kadar Abu Batubara

(a)

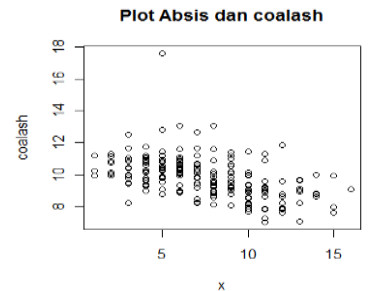

(c)
Plot Ordinat dan Kadar Abu Batubara

(b)

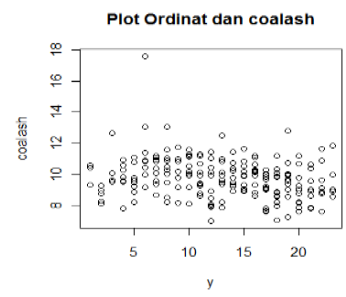

(d) 

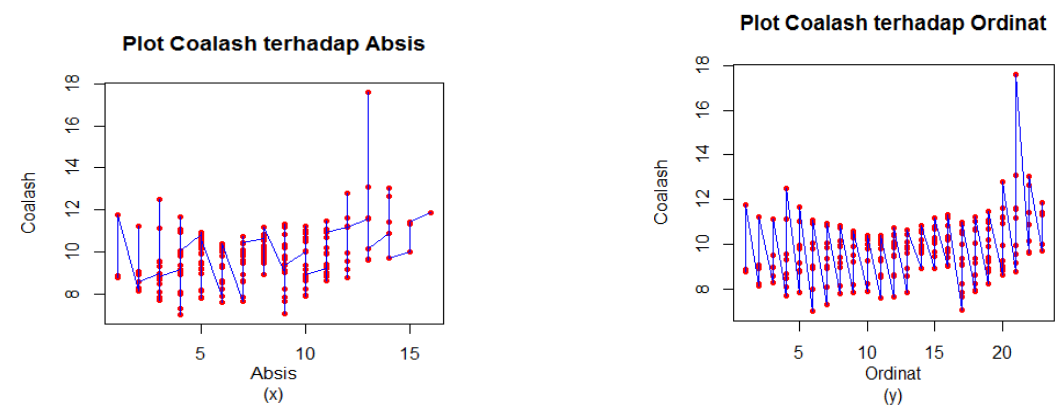

Gambar 4.2 Plot Sebaran Kadar Abu Batubara Berdasarkan Koordinat x,y

Dari hasil plot pada Gambar 4.2 menunjukkan sebuah lengkungan atau dengan kata lain plot dari ke-208 data pada Tabel 4.1 tersebut memiliki kecenderungan trend, sehingga plot data di atas dapat digolongkan ke dalam variabel non-stasioner. Kestasioneran juga dapat dibuktikan dengan ada atau tidaknya sebuah gradasi warna dari data tersebut, sehingga Tabel 4.1 di plotkan kedalam grafik sebagai berikut:

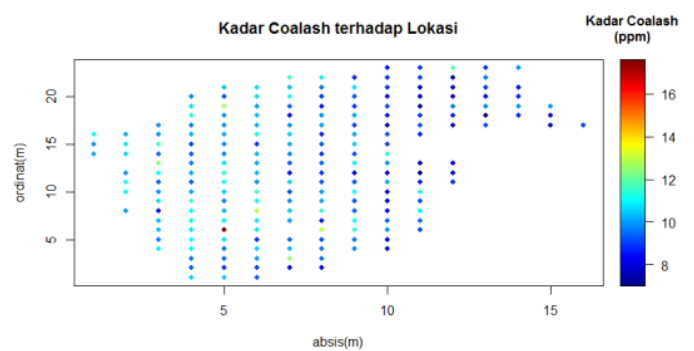

Gambar 4.3 Plot Sebaran Data Kadar Abu Batubara Berdasarkan Titik Koordinat Sampel

Gambar 4.3 memperlihatkan sumbu $x$ dan sumbu $y$ sebagai koordinat lokasi, sedangkan titik-titik yang tersebar menunjukkan kadar abu batubara (Coalash) dan warna dari titik-titik tersebut tergantung dari koordinat lokasinya. Jika diamati secara keseluruhan terdapat gradasi warna dari biru muda ke biru tua, sehingga dapat dikatakan bahwa plot tersebut mengandung kecenderungan trend tertentu karena menunjukkan gradasi warna yang cukup signifikan.

\subsection{Semivariogram Eksperimental Universal Kriging}

Dalam menghitung semivariogram universal kriging perlu dibuat pasangan data tersampel dengan $C(n, 2)$ dimana $n$ adalah banyaknya data. Dari Tabel 4.1 diketahui bahwa titik observasi pengamatan berjumlah 208 tititk sampel, maka dengan $C(n, 2)$ atau $C(208,2)$ dihasilkan sejumlah 21.528 pasangan sampel. Dengan menggunakan program R.3.1.1 pasangan data dapat dilihat dalam plot sebagai berikut:

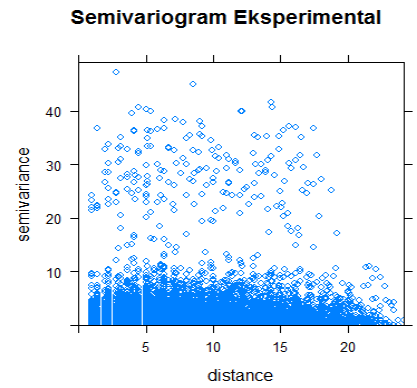

Gambar 4.4 Semivariogram Eksperimental Kadar Abu Batubara

Pada Gambar 4.4 akan sangat sulit dalam menentukan model semivariogram teoritis yang cocok, sehingga diperlukan perhitungan dengan menggunakan semivariogram empiris utuk memperoleh plot rata-rata dari nilai semivarogram $(\gamma(h))$ terhadap jarak $h$. 
Untuk dapat mengetahui model semivariogram teoritis yang cocok digunakan, terlebih dahulu dicari rata-rata dari nilai semivariogramnya, dengan bantuan program R.3.1.1 diperoleh nilai rata-rata semivariogram dari pasangan data yang diperlihatkan dalam tabel berikut:

Tabel 4.3 Nilai Semivariogram Beserta Pasangan Data dan Jaraknya

\begin{tabular}{|c|c|c|c|}
\hline No & Banyaknya pasangan & Jarak & $\begin{array}{c}\text { Semivariogram } \\
\text { Eksperimental }\end{array}$ \\
\hline $\mathbf{1}$ & 369 & 1 & 1.142218 \\
\hline $\mathbf{2}$ & 350 & 1.414214 & 1.254471 \\
\hline $\mathbf{3}$ & 975 & 2.155926 & 1.242048 \\
\hline $\mathbf{4}$ & 300 & 2.828427 & 1.352912 \\
\hline $\mathbf{5}$ & 870 & 3.107626 & 1.202985 \\
\hline $\mathbf{6}$ & 1323 & 3.885617 & 1.241069 \\
\hline $\mathbf{7}$ & 740 & 4.394294 & 1.213062 \\
\hline $\mathbf{8}$ & 1142 & 5.039712 & 1.310886 \\
\hline $\mathbf{9}$ & 1042 & 5.611716 & 1.232801 \\
\hline $\mathbf{1 0}$ & 1345 & 6.226004 & 1.256601 \\
\hline $\mathbf{1 1}$ & 1019 & 6.933935 & 1.138916 \\
\hline $\mathbf{1 2}$ & 939 & 7.363697 & 1.126644 \\
\hline $\mathbf{1 3}$ & 1243 & 8.038779 & 1.128834 \\
\hline $\mathbf{1 4}$ & 609 & 8.554841 & 1.216985 \\
\hline
\end{tabular}

Tabel 4.3 menunjukkan nilai rata-rata dari semivariogram empirirs kadar abu batubara. Hal ini memperlihatkan bahwa dari hasil pengolahan semivariogram eksperimental sebanyak 21.528 pasangan sampel, diperoleh sejumlah titik rata-rata dari pasangan sampel pada masing-masing kelas dan jarak dari setiap pasangan sampel dengan nilai semivariogram empirisnya.

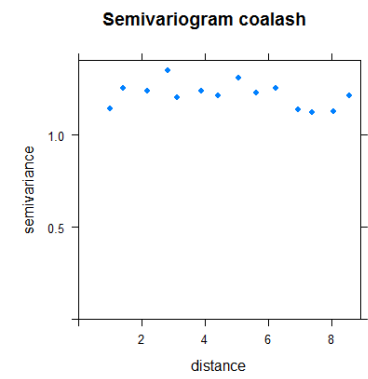

Gambar 4.5 Rata-rata Semivariogram Eksperimental Kadar Abu Batubara

Dari Gambar 4.5 kemudian dilakukan pemilihan model semivariogram teoritis yang terbaik dengan cara fitting model semivariogram teoritis yang sesuai dengan semivariogram pada Gambar 4.5.

\subsection{Fitting Model Semivariogram Teoritis}

\subsubsection{Pendekatan Model Semivariogram Teoritis Spherical}

Dalam program R.3.1.1 model semivariogram teoritis Spherical, nama model ditulis "Sph" yang artinya Spherical. Berikut grafik model semivariogram teoritis Spherical: 


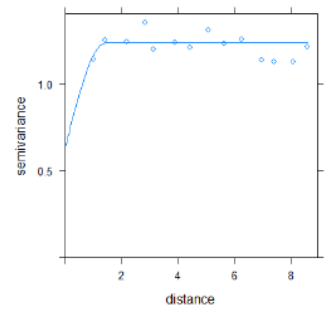

Gambar 4.6 Model Semivariogram Teoritis Spherical

Selanjutnya didapat nilai nugget, sill, dan range dari model semivariogram teoritis Spherical sebagai berikut:

Tabel 4.4 Nilai Nugget Effect, Sill \& Range Model Semivariogram Teoritis Spherical

\begin{tabular}{|c|c|c|c|}
\hline Model & Nugget Effect & Sill & Range \\
\hline Spherical & 0.639837 & 1.406362 & 0.597666 \\
\hline
\end{tabular}

\subsubsection{Pendekatan Model Semivariogram Teoritis Gaussian}

Dalam program R.3.1.1 model semivariogram teoritis Gaussian, nama model ditulis "Gau" yang artinya Gaussian. Berikut grafik model semivariogram teoritis Gaussian:

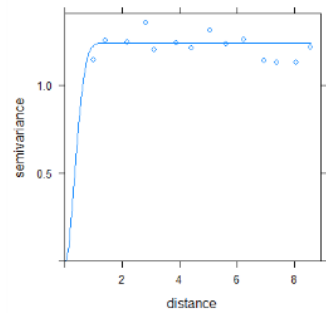

Gambar 4.7 Model Semivariogram Teoritis Gaussian

Selanjutnya didapat nilai nugget, sill, dan range dari model semivariogram teoritis Gaussian sebagai berikut:

Tabel 4.5 Nilai Nugget Effect, Sill \& Range Model Semivariogram Teoritis Gaussian

\begin{tabular}{|c|c|c|c|}
\hline Model & Nugget Effect & Sill & Range \\
\hline Gaussian & 0 & 1.241123 & 0.4820141 \\
\hline
\end{tabular}

\subsubsection{Pendekatan Model Semivariogram Teoritis Eksponensial}

Dalam program R.3.1.1 model semivariogram teoritis Eksponensial, nama model ditulis "Exp" yang artinya Eksponensial. Berikut grafik model semivariogram teoritis Eksponensial:

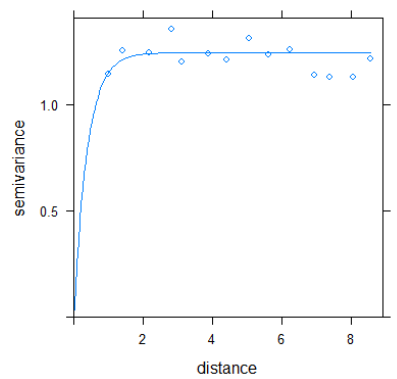

Gambar 4.8 Model Semivariogram Teoritis Eksponensial

Selanjutnya didapat nilai nugget, sill, dan range dari model semivariogram teoritis Eksponensial sebagai berikut: 
Tabel 4.6 Nilai Nugget Effect, Sill \& Range Model Semivariogram Teoritis Eksponensial

\begin{tabular}{|c|c|c|c|}
\hline Model & Nugget Effect & Sill & Range \\
\hline Eksponensial & 0 & 1.24426 & 0.3863591 \\
\hline
\end{tabular}

\subsection{Penentuan Model Semivariogram Teoritis Terbaik}

Model semivariogram teoritis terbaik diperoleh dengan menghitung jumlah kuadrat error di setiap lag. Besarnya error diperoleh dari selisih nilai semivariogram eksperimental dengan nilai semivariogram teoritis disetiap lag. Dengan menggunakan program R.3.1.1 dapat dilihat nilai error dari model semivariogram teoritis adalah sebagai berikut:

Tabel 4.7 Perhitungan Jumlah Kuadrat Error Model Semivariogram Teoritis

\begin{tabular}{|c|c|c|}
\hline \multicolumn{3}{|c|}{ MSE Model Semivariogram Teoritis } \\
\hline Spherical & Gaussian & Eksponensial \\
\hline $\mathbf{0 . 1 4 8 4 2 7}$ & 0.1276118 & $\mathbf{0 . 1 1 1 2 2 6 3}$ \\
\hline
\end{tabular}

Berdasarkan Tabel 4.7 dari ketiga model semivariogram teoritis tersebut, model semivariogram teoritis terbaik yang dipilih adalah model semivariogram teoritis eksponensial, karena memiliki jumlah kuadrat error paling minimum diantara model semivariogram teoritis spherical dan gaussian, dengan jumlah kuadrat error sebesar 0.1112263.

\subsection{Menentukan Orde Persamaan Trend (Drift)}

Universal kriging adalah kriging dari data yang mempunyai kecenderungan trend tertentu.. Dalam paper ini orde dari persamaan trend (drift) dibatasi yaitu orde satu, karena bentuk persamaannya lebih sederhana. Dengan menggunakan program R.3.1.1 dapat dicari koefisien dari persamaan trend (drift) dengan menggunakan perintah tersebut:

$$
>\text { fit }<-\operatorname{lm}(\text { coalash } \sim \mathrm{x}+\mathrm{y})
$$

Dengan menggunakan perintah di atas maka didapat koefisien dari persamaan trend (drift) sebagai berikut:

Tabel 4.8 Koefisien Persamaan Trend (Drift)

\begin{tabular}{|c|c|c|}
\hline \multicolumn{3}{|c|}{ Koefisien } \\
\hline Intercept & $\boldsymbol{x}$ & $\boldsymbol{y}$ \\
\hline 11.24681 & -0.17709 & -0.01039 \\
\hline
\end{tabular}

Berdasarkan Tabel 4.8 diperoleh hasil dari persamaan trend (drift) berode satu sebagai berikut:

$$
m(x)=m(x, y)=11.24681-0.17709 x-0.01039 y
$$

Jika persamaan diatas digambar dalam grafik 3D, akan terlihat pada Gambar 4.9 sebagai berikut:

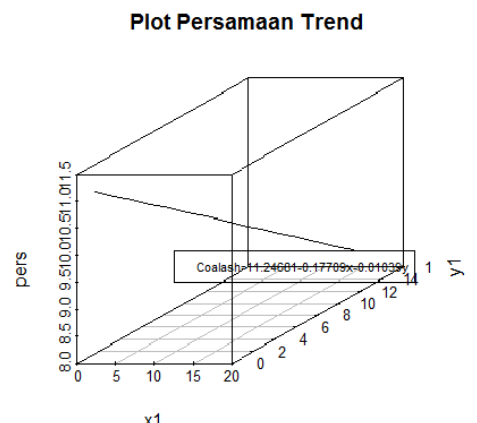

Gambar 4.9 Plot Persamaan Trend (drift)

Pada persamaan trend (drift) berikut $m(x)$ merupakan kadar coalash dan $x$ merupakan koordinat (absis $x$ ) sedangkan $y$ merupakan koordinat (ordinat $y$ ). Artinya ketika nilai dari absis $x$ sama dengan nol dan nilai dari ordinat $y$ sama dengan nol, maka kadar coalash akan sama dengan nilai intercept sebesar 11.24681. Jika nilai dari absis $x$ bergeser satu satuan maka kadar coalash akan berkurang sebesar 0.17709 sedangkan jika ordinat $y$ bergeser satu satuan maka kadar coalash akan berkurang sebesar 0.01039 . 


\subsection{Prediksi Kadar Abu Batubara Menggunakan Metode Universal Kriging}

Data yang akan diprediksi sebanyak 5 lokasi yang sebelumnya telah diketahui lokasi sampel koordinatnya. Kemudian dengan menggunakan program R.3.1.1 maka diperoleh hasil prediksi beserta variansinya. Berikut merupakan tabel hasil prediksi:

Tabel 4.9 Prediksi Kadar Abu Batubara

\begin{tabular}{|c|c|c|c|}
\hline Lokasi & Koordinat & $\begin{array}{c}\text { Prediksi Kadar } \\
\text { Coalash }(\mathbf{p p m})\end{array}$ & Variansi \\
\hline $\mathbf{1}$ & $(2,9)$ & 10.526821 & 0.67866 \\
\hline $\mathbf{2}$ & $(3,3)$ & 10.29427 & 0.794787 \\
\hline $\mathbf{3}$ & $(7,6)$ & 10.459892 & 0.603024 \\
\hline $\mathbf{4}$ & $(13,16)$ & 8.67981 & 0.926539 \\
\hline $\mathbf{5}$ & $(14,24)$ & 9.670573 & 1.038263 \\
\hline
\end{tabular}

Berdasarkan Tabel 4.9 diperoleh bahwa hasil prediksi dan variansi kadar abu batubara di 5 lokasi tidak tersampel nilainya bervariasi, tidak cenderung naik atau tidak cenderung turun, hal ini dikarenakan jenis data yang diprediksi merupakan data yang tidak stasioner atau mempunyai kecenderungan trend (drift) sehingga hasil dari prediksinya bervariasi.

Tabel 4.10 Statistika Deskriptif Data Prediksi Kadar Abu Batubara (Coalash)

\begin{tabular}{|c|c|c|}
\hline & Prediksi Kadar Coalash & Variansi \\
\hline Minimum & 8.680 & 0.6030 \\
\hline 1 Quartil & 9.671 & 0.6787 \\
\hline Median & 10.294 & 0.7948 \\
\hline Mean & 9.926 & 0.8083 \\
\hline 3 Quartil & 10.460 & 0.9265 \\
\hline Maximum & 10.527 & 1.0383 \\
\hline
\end{tabular}

Setelah melakukan beberapa tahapan dalam memprediksi kadar abu batubara di lokasi tidak tersampel dengan menggunakan metode universal kriging, diperoleh model semivariogram teoritis yang terbaik adalah model semivariogram teoritis eksponensial dengan nilai nugget effect sebesar 0, nilai sill sebesar 1.24426 dengan nilai range sebesar 0.3863591 . Proses prediksi dengan metode universal kriging ini merupakan proses prediksi data yang tidak stasioner atau memiliki kecenderungan trend (drift) tertentu, dengan menentukan orde dari persamaan trend (drift) yang berode satu maka didapat nilai untuk absis $x$ sebesar 0.17709 dan niali untuk ordinat $y$ sebesar 0.01039 .

\section{Kesimpulan}

Prosedur GSTAT-R dalam menghitung prediksi di lokasi tidak tersampel dengan metode universal kriging meliputi tahapan sebagai berikut:

a. Pengujian stasioneritas dengan cara plot sebaran data.

b. Proses perhitungan nilai semivariogram eksperimental.

c. Fitting model semivariogram teoritis yang terbaik dengan cara mencari jumlah kuadrat error minimum.

d. Mencari koefisien dari persamaan trend (drift) berorde satu yang melibatkan fungsi lm.

e. Proses prediksi di lokasi tidak tersampel dengan menggunakan metode universal kriging.

Selain itu dengan menggunakan program GSTAT-R yang diaplikasikan pada dataset Coalash, model semivariogram teoritis yang terbaik adalah model semivariogran teoritis eksponensial. Selain itu, nilai kadar abu batubara di 5 lokasi tidak tersampel dapat diestimasi beserta variansi estimasinya dengan nilai yang bervariasi, dikarenakan data yang diestimasi tidak stasioner atau memiliki kecenderungan trend (drift). 


\section{Daftar Pustaka}

[1] Armstrong, M. 1998. Basic Linear Geostatistics. New York: Springer-veriag berlin heidelberg.

[2] Bivand, R. Pebesma, E. and Rubio,V. 2013. Applied Spatial Data Analysis with $R$ (Second Edition). New York. Springer.

[3] Cressie, N. A. C. 1993. Statistics For Spatial Data. New York: John Wiley and Sons, Inc. New York.

[4] Olea, R. A. 1999. Geostatistics for engineers and earth scientists. Kluwer Academic Publishers. United States of America. 
